\title{
XopR, a Type III Effector Secreted by Xanthomonas oryzae pv. oryzae, Suppresses Microbe-Associated Molecular Pattern-Triggered Immunity in Arabidopsis thaliana
}

\author{
Chiharu Akimoto-Tomiyama, ${ }^{1}$ Ayako Furutani, ${ }^{1}$ Seiji Tsuge, ${ }^{2}$ Erica J. Washington, ${ }^{3}$ Yoko Nishizawa, ${ }^{4}$ \\ Eiichi Minami, ${ }^{4}$ and Hirokazu Ochiai ${ }^{1}$ \\ ${ }^{1}$ Plant-Microbe Interaction Research Unit, Division of Plant Sciences, National Institute of Agrobiological Sciences, Tsukuba, \\ Ibaraki 305-8603, Japan; ${ }^{2}$ Laboratory of Plant Pathology, Graduate School of Agriculture, Kyoto Prefectural University, \\ Kyoto, Japan; ${ }^{3}$ Department of Biology, University of North Carolina, Chapel Hill 27599, USA; ${ }^{4}$ Disease Resistant Crops \\ Research and Development Unit, Genetically Modified Organism Research Center, National Institute of Agrobiological \\ Sciences, Tsukuba, Japan
}

Submitted 14 June 2011. Accepted 21 December 2011.

Xanthomonas oryzae pv. oryzae is the causal agent of bacterial blight of rice. The XopR protein, secreted into plant cells through the type III secretion apparatus, is widely conserved in xanthomonads and is predicted to play important roles in bacterial pathogenicity. Here, we examined the function of XopR by constructing transgenic Arabidopsis thaliana plants expressing it under control of the dexamethasone (DEX)-inducible promoter. In the transgenic plants treated with DEX, slightly delayed growth and variegation on leaves were observed. Induction of four microbeassociated molecular pattern (MAMP)-specific early-defense genes by a nonpathogenic $X$. campestris pv. campestris hrcC deletion mutant were strongly suppressed in the XopRexpressing plants. XopR expression also reduced the deposition of callose, an immune response induced by flg22. When transiently expressed in Nicotiana benthamiana, a XopR::Citrine fusion gene product localized to the plasma membrane. The deletion of $X o p R$ in $X$. oryzae pv. oryzae resulted in reduced pathogenicity on host rice plants. Collectively, these results suggest that XopR inhibits basal defense responses in plants rapidly after MAMP recognition.

Most gram-negative pathogenic bacteria have a type III secretion system (T3SS) that is required for infection of animal and plant cells (Alfano and Collmer 1997; Büttner and Bonas 2006; Büttner and He 2009). Early following of the infection of host plants, pathogenic bacteria secrete type III effectors (T3E) via a T3SS. In plant-pathogenic bacteria, the components of the T3SS are encoded by hrp (hypersensitive response and pathogenicity) genes (Alfano and Collmer 1997). Bacterial mutants lacking a functional T3SS cannot induce a hypersensitive response and are unable to infect resistant host and nonhost plants, indicating that successful infection requires translocation of T3E (Alfano and Collmer 2004).

Host plants recognize pathogenic agents via microbe-associ-

Current address for A. Furutani: Gene Research Center, Ibaraki University, Inashiki, Japan.

Corresponding author: C. Akimoto-Tomiyama; Telephone and Fax:+8129-838-7005; E-mail: akimotoc@ affrc.go.jp ated molecular patterns (MAMPs), such as flagellin, chitin, and elongation factor Tu. These MAMPs bind to specific receptors on the cell membrane, initiating a basal immune response by activating immediate intracellular responses, including the rapid induction of $\mathrm{Ca}^{2+}$ flux, production of nitric oxide and reactive oxygen species, expression of defense-related genes, and deposition of callose, which strengthen the plant cell wall (Abramovitch et al. 2006; Brown et al. 1995; He et al. 2007; Kaku et al. 2006). These basal defense responses can also be induced by a purified 22-amino acid flagellin peptide (flg22) (Zipfel et al. 2004). Specific receptors for flg22 have been identified in both Arabidopsis (FLS2) (Gomez-Gomez and Boller 2002) and rice (OsFLS2) (Takai et al. 2008).

More than 50 potential T3E families have been identified in plant-pathogenic bacteria such as Xanthomonas spp. and Pseudomonas syringae. (Grant et al. 2006; Lindeberg et al. 2005; White et al. 2009). Functional analysis of T3E from plant phytobacteria indicate that T3E promote pathogen growth by altering host processes in a way that optimize the inter- and intracellular environments and promote disease development by suppressing host defense responses (Boller and He 2009). Although the hrp gene cluster of bacteria and the plant basal immunity system are widely conserved, T3E vary widely, suggesting that they play significant roles in bacterial pathogenicity in order to adapt to various host plants.

Xanthomonas oryzae pv. oryzae is the causal agent of bacterial leaf blight of rice, which is globally one of the most important crops. On the basis of sequence similarities, T3E secreted by Xanthomonas spp. are classified into 39 families, reflecting the genetic diversity of virulence weaponry of the pathogens (White et al. 2009). Transcription activation-like (TAL) proteins, also called AvrBs3/PthA family proteins, are a major family of Xanthomonas T3E that induce the transcription of plant genes by binding to target gene promoters (Kay and Bonas 2009). X. oryzae pv. oryzae strains harbor multiple TAL genes. For example, there are 16 TAL genes in $X$. oryzae pv. oryzae MAFF311018, 19 in X. oryzae pv. oryzae PXO99A, and six in X. oryzae pv. oryzae KACC10331 (Lee et al. 2005; Ochiai et al. 2005; Salzberg et al. 2008). The TAL family is also conserved in several other Xanthomonas species and pathovars. Although the primary function of TAL proteins is to promote plant susceptibility to bacterial infection, in some cases, plants 
have evolved to recognize them and use them to trigger resistance ( $\mathrm{Gu}$ et al. 2005). In fact, a number of TAL effectors are known to act as avirulence factors, e.g., AvrXa7, AvrXa10, and AvrXa27 (Gu et al. 2005; Yang et al. 2005). The features of TAL effectors are well characterized and their specific binding mechanism has been applied to novel efficient genome editing system for higher eukaryotes (Boch et al. 2009; Miller et al. 2011; Scholze and Boch 2011).

Many efforts have been made to identify and characterize Xanthomonas outer proteins (Xops), which are non-TAL effector proteins of xanthomonads. The functions of some effectors, such as XopN, XopJ, and XopD, have been predicted by comparison with sequences or motifs from T3E with known functions (Bartetzko et al. 2009; Kim et al. 2009). XopN from $X$. campestris pv. vesicatoria had been shown to suppress pathogen-associated molecular pattern (PAMP)-triggered immunity and interact with atypical receptor-like kinase 1 and four tomato 14-3-3 isoforms (Kim et al. 2009). XopD from X. campestris pv. vesicatoria has been shown to function in the in vitro "de-SUMOlyzation" of plant proteins (Kim et al. 2008). XopJ from $X$. campestris pv. vesicatoria is structurally similar to the C55 group of cysteine protease and has been proposed to be involved in the ubiquitin/proteasome system and to be capable of removing SUMO proteins, resulting in the destabilization or inactivation of SUMOlyated proteins (Bartetzko et al. 2009). However, the precise mechanisms of non-TAL effectors remain largely unknown, especially for T3E that lack structures or sequences similar to known motifs.

In $X$. oryzae pv. oryzae, we previously identified 16 non-TAL effector proteins in strain MAFF311018 based on complete sequence data (Furutani et al. 2009), but their functions remain unknown. Recently, Song and Yang (2010) reported the identification and mutational analysis of 18 non-TAL T3E from the Philippine strain PXO99A. In this study, two identical copies of XopZ $Z_{\text {PXO99 }}$ were shown to be required for full virulence of strain PXO99A. Transient expression of XopZ $\mathrm{PXO99}_{\text {in Nico- }}$ tiana benthamiana leaves suppressed callose deposition induced by a T3SS mutant of PXO99A, indicating XopZ $\mathrm{PXO99}_{\text {}}$ suppressed host innate immunity during $X$. oryzae pv. oryzae infection (Song and Yang 2010).

Gene XOO_4134 of strain MAFF311018 encodes a T3E XopR that is well conserved in xanthomonads but not in other phytobacteria, such as Pseudomonas spp. and Ralstonia solanacearum (Furutani et al. 2009). XopR is highly conserved in three strains of $X$. oryzae pv. oryzae, XOO_4134 for MAFF311018, XO04391 for KACC10331, and PXÖ03819 for PXO99A, and they exhibit more than $99 \%$ homology to each other. Our previous study showed that gene XOO_4134 was coregulated with the hrp genes and the product was translocated into plant cells in T3SS-dependent manner (Furutani et al. 2009). XopR is a 437-amino acid protein that lacks known motifs or domains, and its function has not been elucidated. In the current study, we generated transgenic Arabidopsis lines expressing XopR. Our results suggest that XopR functions as a repressor of MAMP-induced plant innate immune responses.

\section{RESULTS}

Generation of XopR-expressing Arabidopsis plants.

To characterize one or more of the functions of XopR in plants, we generated two independent transgenic lines (6-2 and 7-5) expressing full-length XopR with a C-terminal hemagglu-
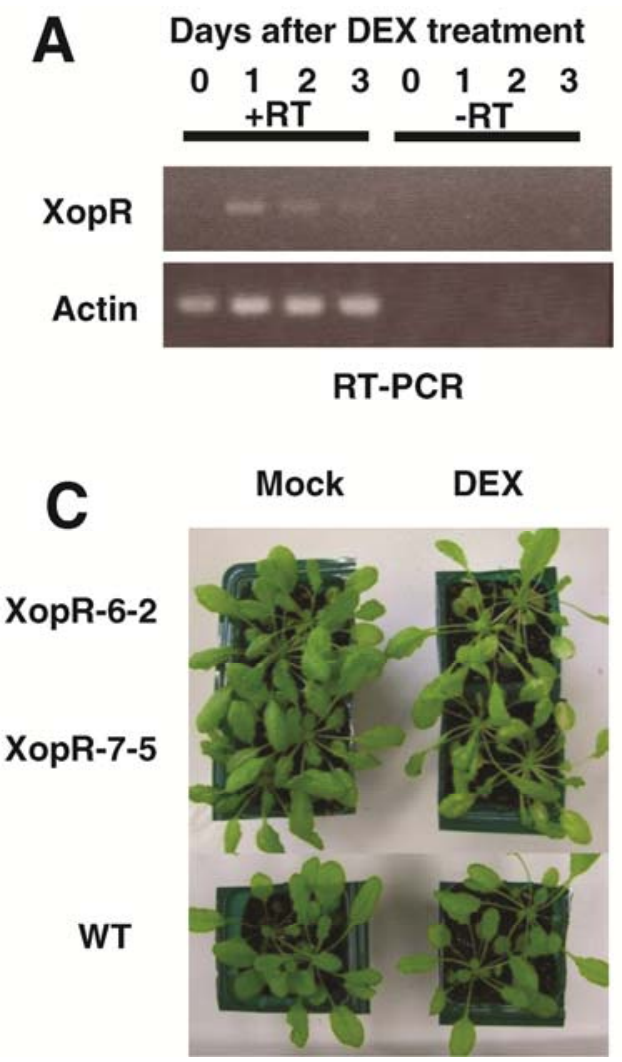

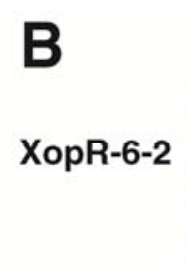

XopR-7-5

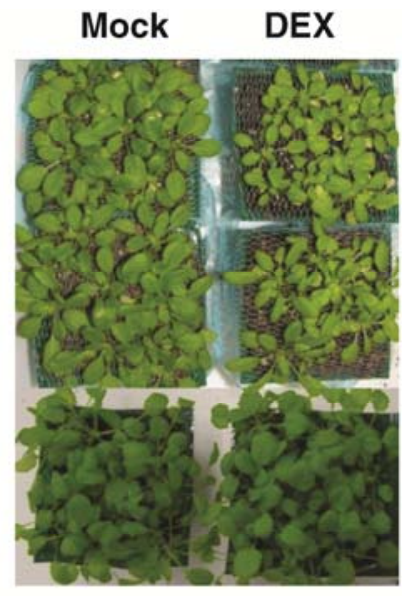

D
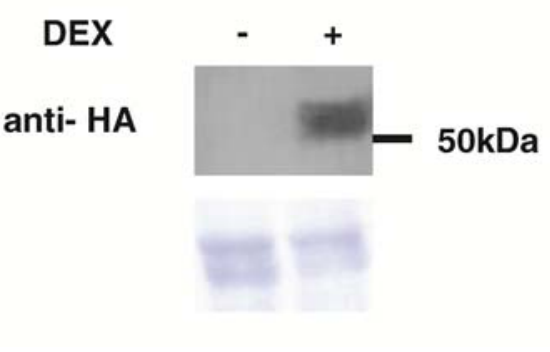

Fig. 1. Morphological phenotype of XopR transgenic Arabidopsis. A, XopR expression was confirmed by reverse transcription-polymerase chain reaction. Results were similar in the two transgenic lines. RT = reverse transcription. B and C, Two independent lines of XopR transgenic (XopR-6-2 and XopR-7-5) and nontransgenic (WT) plants 10 days after treatment with $30 \mu \mathrm{M}$ dexamethasone (DEX) or vehicle alone (Mock). XopR expression was induced in B, 3-week-old or C, 6-week-old plants. Scale bars $=1 \mathrm{~cm}$. D, Immunoblot assay of XOPR-hemagglutinin (HA) protein (detected by anti-HA antibodies) in 6-week-old XopR transgenic plants 2 days after DEX or mock treatment. Results were similar in the two transgenic lines. 
tinin (HA) tag under the control of the dexamethasone (DEX)inducible promoter in Arabidopsis thaliana ecotype Col-0. DEX-induced XopR expression was detected in the transgenic lines by semiquantitative reverse transcription-polymerase chain reaction (RT-PCR) (Fig. 1A). In 3-week-old plants, induction of XopR expression with DEX arrested the growth of both transgenic lines (Fig. 1B). In 6-week-old plants, treatment of leaves with DEX triggered a variegated phenotype (Fig. 1C), although they eventually recover normal green leaves. DEX had no effect on nontransgenic wild-type Col-0 plants. XopR protein accumulation was confirmed at predicted size, according to immunoblot analysis (Fig. 1D).

\section{Expression of XopR in Arabidopsis enhances proliferation} of the T3SS-defective $h r c C$ mutant

of $X$. campestris pv. campestris.

We generated a T3SS-defective $h r c C$ mutant of $X$. campestris pv. campestris ATCC33913 that is defective in $h r c C$ encoding a component of the T3SS apparatus, and we used it to examine the effects of XopR on the growth of Arabidopsis. Because Arabidopsis ecotype Col-0, which was used for the construction of transgenic lines, is resistant to X. campestris pv. campestris ATCC33913 (Meyer et al. 2005), we used Arabidopsis Sf-2 ecotype, susceptible to strain ATCC33913 (Meyer et al. 2005), to confirm the $h r c C$ mutant lacks virulence. Indeed, the mutant was not pathogenic in Sf-2 plants (data not shown).

We next measured bacterial growth following inoculation with the $h r c C$ mutant in both transgenic lines harboring XopR.
Induction of XopR expression with DEX enhanced bacterial growth in both transgenic lines at 3 days postinoculation (Fig. $2 \mathrm{~A}$ and $\mathrm{B})$. However, no visible symptom was observed after hrcC mutant inoculation. Growth of the mutant on the wildtype Col-0 plants was similar in the presence or the absence DEX (Fig. 2C), indicating that DEX itself does not affect $X$. campestris pv. campestris proliferation. These results suggest that XopR contributes to the growth of nonpathogenic bacteria in Arabidopsis.

\section{Transgenic expression of XopR suppresses early defense-response genes induced by the T3SS-defective $h r c C$ mutant.}

Plants recognize bacterial attacks through receptors that bind MAMPs. MAMP recognition is followed by an immediate defense reaction, such as activation of early defense-response genes. He and associates (2006) selected four MAMP-specific early defense-response genes (At 1 g51890, leucine-rich repeat protein kinase; At2g17740, cysteine/histidine-rich $\mathrm{C} 1$ domain family protein; $F R K 1$, Flg22-induced receptor-like kinase 1; and At5g57220, member of CYP81F) that are induced by MAMPs from both virulent and avirulent bacteria but not by other stressrelated signals. We tested whether the induction of these four genes by the $h r c C$ mutant was affected by XopR expression. As shown in Figure 3, real-time PCR analysis revealed that all four genes were induced even $2 \mathrm{~h}$ postinoculation (hpi) with the $h r c C$ mutant in DEX-untreated plants. The expression levels of these genes were further increased at $6 \mathrm{hpi}$. In DEX-treated plants, on

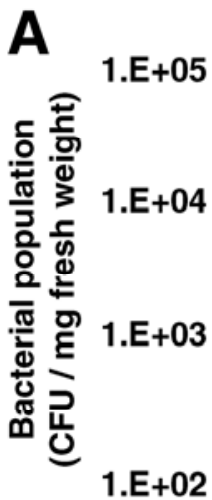

1.E+02

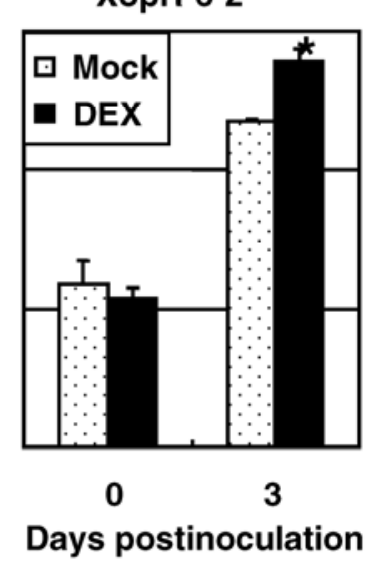

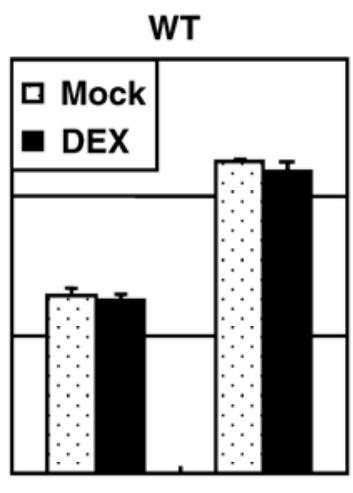

0

3
B

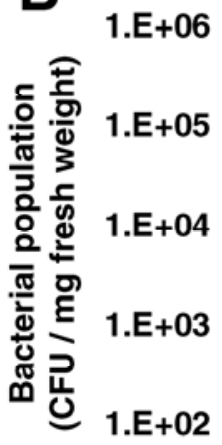

1.E+02

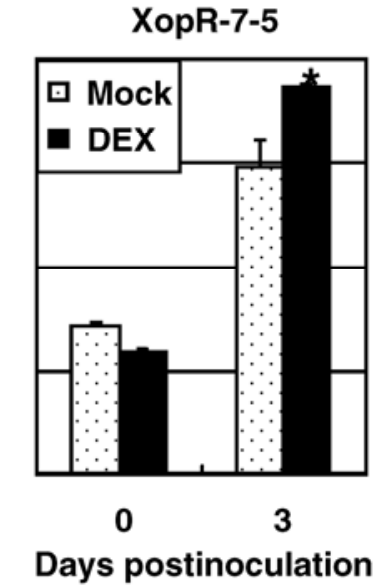

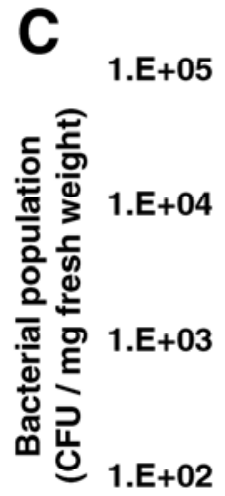

Days postinoculation

Fig. 2. Enhanced multiplication of type III secretion system-defective $h r c C$ mutant bacteria in two independent XopR-expressing plants. A, Bacterial multiplication was measured in XopR-6-2, B, XopR-7-5, or C, wild-type (WT) plants. Five fully expanded leaves of each plant were inoculated by piercing three holes in the central vein with a needle dipped in a suspension of Xanthomonas campestris pv. campestris hrcC mutant bacteria $\left(10^{9} \mathrm{CFU} / \mathrm{ml}\right) . * P<0.001 \mathrm{vs}$. vehicle control (Mock) by Student's $t$ test. Results are representative of at least three experiments per condition. 
the other hand, the four genes were not induced at 2 or 6 hpi by inoculation with the hrcC mutants. The four genes were not induced under conditions of XopR expression without inoculation with the mutant. Furthermore, in nontransgenic plants, the expression of the four genes was not suppressed by DEX (data not shown). Taken together, these results show that XopR represses the expression of MAMP-triggered early-defense genes. We also found that the level of XopR induction in trans- genic plants treated with DEX and the $h r c C$ mutant were lower at $6 \mathrm{hpi}$ than at $2 \mathrm{hpi}$, although we were unable to determine the reason for this difference.

Transgenic expression of XopR suppresses flg22-induced callose deposition.

MAMPs induce the deposition of callose-rich papillae at the cell wall as part of the innate immune response to pathogens.
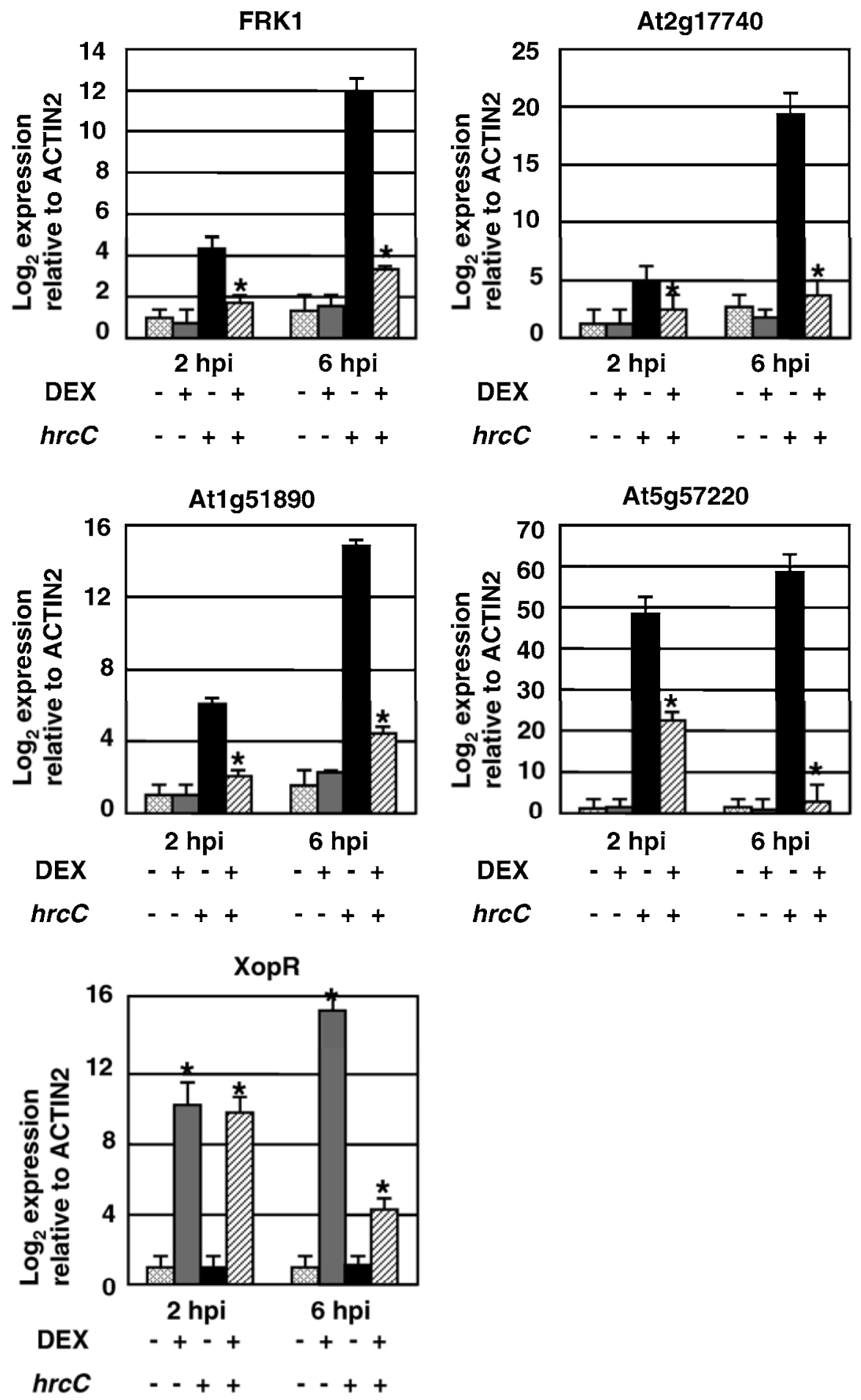

Fig. 3. Transgenic expression of XopR suppresses the induction of microbe-associated molecular pattern (MAMP) marker genes by the type III secretion system-defective $h r c C$ mutant. Expression of MAMP marker genes in XopR transgenic plants (XopR-7-5) was measured by real-time reverse transcriptionpolymerase chain reaction. Plants were pretreated with or without dexamethasone (DEX) (mock treatment) for $24 \mathrm{~h}$ before inoculation. Plant samples were harvested 2 and $6 \mathrm{~h}$ postinoculation (hpi) with the $X$. campestris pv. campestris hrcC mutant $(h r c C)$ or with vehicle alone. $* P<0.001$ vs. mock treatment controls by Student's $t$ test. Results are representative of three experiments. 
Callose is a $\beta$-1,3-glucan polymer that strengthens and seals weak or compromised sections of plant cell walls at the site of pathogen attack. Callose deposits can be observed by staining with aniline blue. Callose deposition in Arabidopsis seedlings can be stimulated by flg22, a MAMP derived from bacterial flagella that binds to a specific receptor called FLS2 (Zipfel et al. 2004). Recently, Clay and associates (2009) showed that flg22 triggers callose deposition in Arabidopsis seedlings by activating the 4-methoxylation of indol-3-ylmethylglucosinolate by CYP81F2 (At5g57220), a cytochrome P450 monooxygenase. Given that $h r c C$ mutant-induced expression of CYP81F2 was blocked in the presence of XopR (Fig. 4), we suspected that XopR plays a role in PAMP-induced callose deposition. In Arabidopsis leaves in which XopR expression was not induced, high levels of callose deposition was observed $8 \mathrm{~h}$ after infiltration with $1 \mu \mathrm{M}$ flg22 (Fig. 4A and B). In contrast, the deposition was decreased in both transgenic lines when XopR expression was induced (Fig. 4B).

\section{XopR::Citrine localizes to the plasma membrane when transiently expressed in epidermal cells of $N$. benthamiana.}

To determine where XopR localizes, we generated a Citrinetagged full-length XopR that is expressed under control of the estrogen-inducible promoter and transiently expressed the construct in $N$. benthamiana. Citrine is an engineered yellow fluorescent protein (YFP) that increases the acid stability of the protein and reduces the chloride sensitivity compared with other YFP. Citrine fluorescence was observed by confocal laser scanning microscopy. One day after treatment with estradiol, strong Citrine fluorescence was observed at the plasma membrane in XopR::Citrine-expressing plants (Fig. 5A and B). Citrine fluorescence was not observed at the nucleus (Fig. 5B). In the absence of estradiol, Citrine fluorescence was not observed (data not shown). We also extracted total protein from the leaves of XopR::Citrine-expressing plans, fractionated them into soluble and microsomal fractions, and analyzed the fractions by Western blot, using an antibody to green fluorescent protein (GFP) that also reacts with Citrine protein. Citrinetagged XopR was localized in the microsomal fraction at the predicted size (Fig. 5C), in agreement with microscopic observation that it was present in the plasma membrane.

\section{XopR mutant shows reduced pathogenicity on rice.}

XopR deletion mutant of $X$. oryzae pv. oryzae was prepared in order to test XopR contribution to pathogenicity. XopR deletion mutant or wild-type $X$. oryzae pv. oryzae was inoculated on two compatible rice cultivars (IR24 and Nipponbare), using the leaf-clipping method, and lesion area was measured 10 days after inoculation. As shown in Figure 6A and B, both IR24 and Nipponbare rice lines exhibited reduced lesion development when inoculated with $x o p R$ mutant, as compared with those inoculated with wild-type $X$. oryzae pv. oryzae. The introduction of XopR plasmid restored pathogenicity (Fig. 6A and $\mathrm{B}$ ), indicating $\mathrm{XopR}$ is required for full $X$. oryzae $\mathrm{pv}$. oryzae virulence.

\section{DISCUSSION}

The $X$. oryzae pv. oryzae MAFF311018 genome includes at least 16 non-TAL type effectors and 16 effectors of the TAL family (Furutani et al. 2009; Ochiai et al. 2005). We report here that XopR is involved in the suppression of innate immunity in A. thaliana, although the function of XopR within the plant defense system remains to be determined.

We developed Arabidopsis plants in which XopR expression was induced by DEX. Induction of XopR expression caused a delay in growth and appearance of a variegated phenotype in the plants. We also tried to develop plants that constitutively express XopR but were unsuccessful. We suspect that expression of higher protein levels in transgenic plants than secreted by bacteria in the normal infection process disrupted not only the defense system but also the reproductive system of the plants.

Transiently expressed XopR::Citrine fusion protein accumulated on the plasma membrane of $N$. benthamiana. Functional analyses of various T3E from Psudomonas spp., one of the most extensively studied plant phytobacteria, show that T3E proteins are widely spread within the cell and that where they localize correlates well with their function. HopAI1, a cytosolic protein, is a phosphothreonine lyase that dephosphorylates

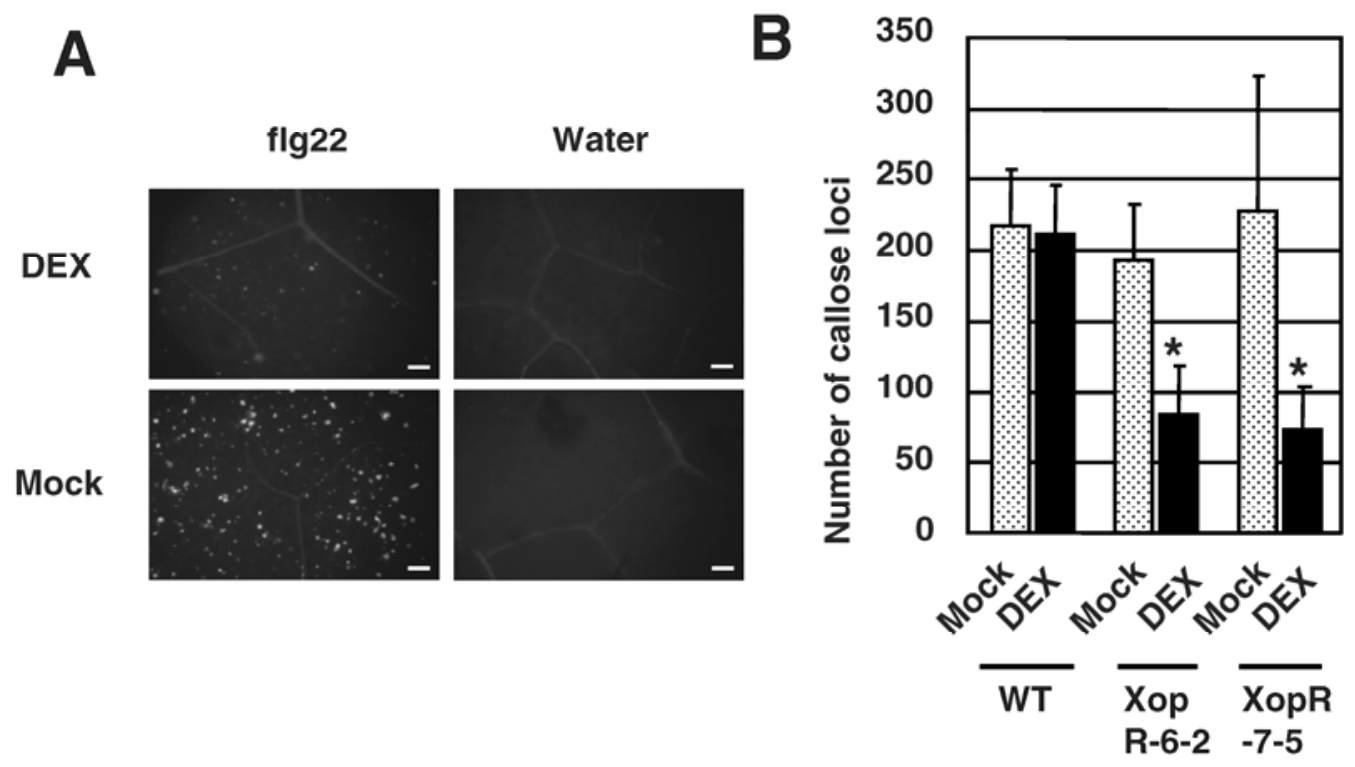

Fig. 4. XopR suppresses flg22-induced callose deposition. Papilla-associated callose deposition was assessed in XopR-6-2 and XopR-7-5 transgenic plants and in wild-type (WT) plants. Plants were pretreated with dexamethasone (DEX) or vehicle (Mock) and then infused with $1 \mu \mathrm{M}$ flg22 or water. A, The leaves from XopR-7-5 plants were stained for callose deposits $8 \mathrm{~h}$ postinfusion and were observed by fluorescence microscopy. Scale bars $=0.1 \mathrm{~mm}$. B, Average number of callose deposits per field of view in XopR transgenic and nontransgenic plants. ${ }^{*} P<0.001$ vs. mock treatment controls by Student's $t$ test. Results are representative of two experiments. 
mitogen-activated protein kinases MPK3 and MPK6 to terminate MAMP signaling (Zhang et al. 2007). In the chloroplast, HopI1 interacts with Hsp70, causing chloroplast thylakoid structure remodeling and suppressing salicylic acid accumulation, a plant hormone key to defense responses (Jelenska et al. 2007). Therefore, like AvrPto and AvrPtoB from $P$. syringe, which inhibit MAMP recognition or signal transduction, XopR might impair defense responses occurring immediately after recognition of MAMPs by their membrane receptors. XopR inhibited the callose deposition caused by flg22, indicating XopR act on flg22 perception or the signal transduction process. Membrane localization of a number of Xanthomonas effectors, including XopE1, XopE2, and XopJ, depends on N-myristoylation motifs, which mediate fatty acid modification in eukaryotic cells (Thieme et al. 2007). N-myristoylation motifs also anchor some Pseudomonas effectors, such as AvrB, AvrRpm1, AvrPphB, AvrPto, and HopF2, to the host cell plasma membrane (Göhre et al. 2008; Nimchuk et al. 2000; Robert-Seilaniantz et al. 2006; Shan et al. 2000; Xiang et al. 2008). Interestingly, the myristoylation motif of these effectors is required for avirulence and virulence functions (Nimchuk et al. 2000; Robert-Seilaniantz et al. 2006; Shan et al. 2000; Thieme et al. 2007). However, XopR does not have a myris- toylation site at the $\mathrm{N}$-terminus nor an internal sequence, indicating that it might have functions distinct from known plasma membrane effectors and could play a novel role in plant defenses against pathogens. Two T3E from $P$. syringae pv. tomato DC3000, HopC1 and HopN1, are localized at the plasma membrane without a N-myristoylation site by an unknown mechanism (Dowen et al. 2009). Recently, it was reported that coiled-coil (CC) domains enhanced the membrane association of Salmonella T3E (Knodler et al. 2011). XopR is predicted to contain a CC-like motif between amino acid residues 271 and 300 based on the analysis using the COILS prediction program. This CC-like domain may contribute to the membrane recruit. Detailed analyses on XopR protein behavior in planta are needed to clarify XopR function.

Our results suggest that $X$. oryzae pv. oryzae T3E XopR functions as a repressor of early defense events of plant innate immunity, at least in A. thaliana. Similar defense mechanisms are conserved in both rice and A. thaliana. For example, all higher plants have homologs of FLS2, and the rice homolog acts as a flagellin receptor (Takai et al. 2008). Likewise, both CERK1 (Miya et al. 2007) and OsCERK1 (Shimizu et al. 2010) are essential for chitin elicitor signaling in Arabidopsis and rice, respectively. Therefore, in rice, XopR might function

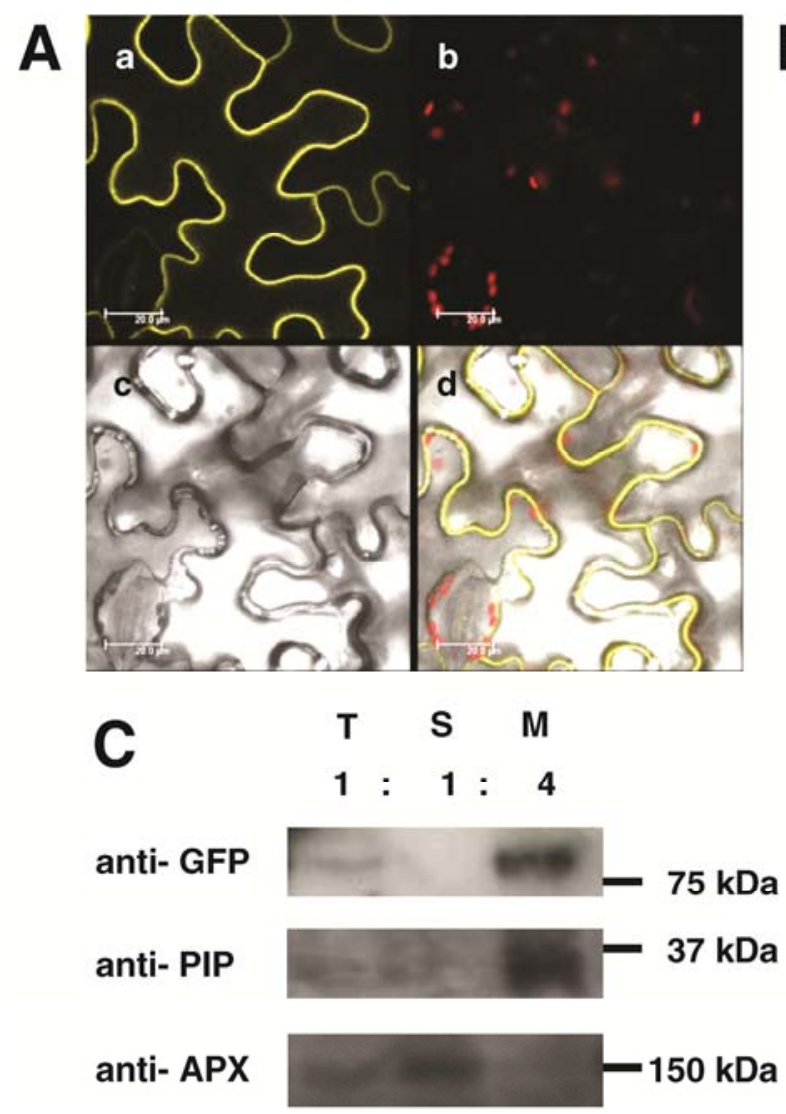

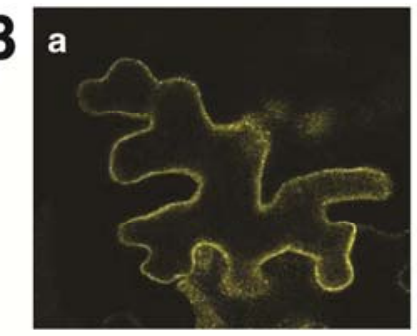
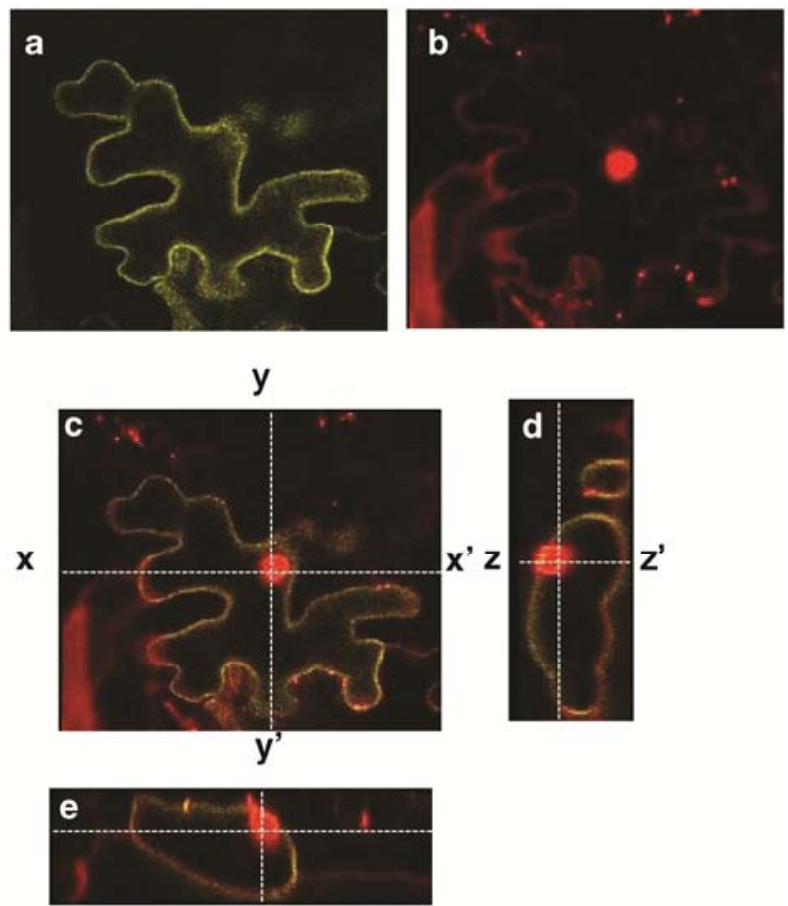

Fig. 5. XopR::Citrine is localized on membranes not at the nucleus. Agrobacterium tumefaciens EHA105, which mediates T-DNA-based transfer of XopR::Citrine, was co-infused into Nicotiama benthamiana leaves at an optical density at $600 \mathrm{~nm}$ of 1.0 and with HC-Pro in pMD1 at an optical density at $600 \mathrm{~nm}$ of 0.1. A, Samples were observed by confocal microscopy 1 day after Estradiol treatment. a, Citrine fluorescence is shown in yellow; b, chlorophyll autofluorescence is shown in red; c, bright field image; d, merged view. Scale bars $=20.0 \mu \mathrm{m}$. The fluorescence was stable at least 3 days after Estradiol treatment. B, Samples were stained using propidium iodide solution $(10 \mu \mathrm{g} / \mathrm{ml}$ propidium iodide [Sigma-Aldrich], $1 \times$ phosphate-buffered saline [Nacalai tesque, Kyoto, Japan], $0.1 \%$ Triton-100 [Sigma-Aldrich]) with $2 \times$ vacuum de-aeration followed by $1 \%$ Triton- 100 treatment. a, Citrine fluorescence is shown in yellow; b, propidium iodide fluorescence is shown in red; $\mathbf{c}$, merged view; $\mathbf{d}$, cross-sectional view of c along the line $\mathrm{y}$-y'; e, cross-sectional view of c along the line $\mathrm{x}-\mathrm{x}^{\prime} . \mathrm{X}-\mathrm{x}^{\prime}=140 \mu \mathrm{m} ; \mathrm{y}-\mathrm{y}^{\prime}=121 \mu \mathrm{m} ; \mathrm{z}-\mathrm{z}^{\prime}=43.1 \mu \mathrm{m}$. A and B, For microscopic observation, $561 \mathrm{~nm}$ excitation and 600 to $650 \mathrm{~nm}$ emission for propidium iodide detection, $514 \mathrm{~nm}$ excitation and 520 to $540 \mathrm{~nm}$ emission for Citrine fluorescence and $514 \mathrm{~nm}$ excitation and 650 to $700 \mathrm{~nm}$ emission for chlorophyll autofluorescence were used. C, Western blotting for Citrine. Western blotting was performed using an antibody to green fluorescent protein (GFP) that also reacts with Citrine. Free Citrine protein was not detected by this assay. Rabbit anti-aquaporin (PIP) antibodies and anti-cytosolic ascorbate peroxidase (APX) antibodies were used as fractionation control. Lanes contain $50 \mu \mathrm{g}$ of total protein extract (T), soluble fraction (S) from $50 \mu \mathrm{g}$ of total protein extract, or microsomal fraction (M) from $200 \mu \mathrm{g}$ of total protein. 
as a repressor of plant innate immunity. In support of this idea, our inoculation test revealed that the XopR mutant of $X$. oryzae pv. oryzae is less virulent than the parental strain in susceptible rice cultivars IR24 and Nipponbare. However, Song and Yang (2010) reported that mutation of XopR in another X. oryzae pv. oryzae strain, PXO99A, does not reduce pathogenicity in rice cultivar IR24. The different findings might be due to the three amino acids that differ between the XopR from MAFF 311018 and that from PXO99A. Alternatively, the results may have been due to differences in assay conditions.

Based on a BLAST search, XopR is conserved in xanthomonads, such as $X$. campestris pv. campestris, $X$. oryzae pv. oryzicola, $X$. campestris pv. vasculorum, $X$. campestris pv. musacearum, $X$. campestris pv. vesicatoria, $X$. axonopodis pv. citri, which shows wide host variety. $X$. campestris pv. campestris causes black rot in cruciferae such as members of genera Arabidopsis and Brassica. Like X. oryzae pv. oryzae, X. campestris pv. campestris is a vascular pathogen that produces extracellular polysaccharides that impede water movement through xylem tissues. $X$. campestris pv. campestris also encodes $\mathrm{XopR}_{\mathrm{Xcc}}$, and our preliminary data has shown that it is secreted inside the plant host in a T3SS-dependent manner. XopR $\left(\mathrm{XOO}_{4} 4134\right)$ is a 437-amino acid protein, whereas $\mathrm{XopR}_{\mathrm{Xcc}}$ (XCC0258) is a 411-animo acid protein, and their amino-acid sequences are $33 \%$ identical. Although $\mathrm{XopR}_{\mathrm{Xcc}}$ has not been previously shown to play a role in $X$. campestris pv. campestris virulence and its function has not been previously reported, our results suggest that $\mathrm{XopR}_{\mathrm{Xcc}}$ may play a similar role in pathogen-plant interactions, namely, disruption of the early defense system in host plants. Further studies are needed to elucidate the precise function of XopRs. Such studies may identify novel common early defense signaling pathways in both rice and Arabidopsis.

\section{MATERIALS AND METHODS}

\section{Bacterial strains and media.}

X. oryzae pv. oryzae MAFF311018 (Ochiai et al. 2005) and $X$. campestris pv. campestris ATCC33913 (da Silva et al. 2002) were grown at $28^{\circ} \mathrm{C}$ in nutrient broth-yeast extract (NBY) medium (Vidaver 1967). Escherichia coli strains and Agrobacterium tumefaciens were grown in Luria broth (Miller 1972) at 37 and $28^{\circ} \mathrm{C}$, respectively. All media were supplemented with antibiotics at the following concentrations: rifampicin, $20 \mu \mathrm{g} / \mathrm{ml}$; ampicillin, $50 \mu \mathrm{g} / \mathrm{ml}$; cycloheximide, $50 \mu \mathrm{g} / \mathrm{ml}$; kanamycin, 50 $\mu \mathrm{g} / \mathrm{ml}$ for $E$. coli and $25 \mu \mathrm{g} / \mathrm{ml}$ for $X$. campestris pv. campestris, $X$. oryzae pv. oryzae, and agrobacteria.

\section{Construction of bacteria mutants.}

The 1.5-kb upstream and 1.8-kb downstream regions of the hrcC gene were amplified from $X$. campestris pv. campestris ATCC33913 (da Silva et al. 2002) using the following primer sets (restriction sites underlined): $h r c C_{-}$up_S (5'-AAGAATTC TCAGCACCTGGAGGACGTTGCA-3') and $h r c C$ _up_AS ( $5^{\prime}$ AAGGTACCTGCGTTCCCTCTGCGAGGAAGT-3') for the upstream region; and $h r c C$ _down_S (5'-AAGGTACCGCA ACGCGTCGGGCTGCACGCG - 3') and $h r c C$ _down_AS (5'GGAAGCTTGGACTGTATCAACGTCACGCAG-3') for the downstream region. After treatment with the appropriate restriction enzymes, fragments were cloned into the EcoRI/KpnIor KpnI/HindIII-digested pUC19 (Vieira and Messing 1987) to obtain pUChrcCup or pUChrcCdown, after which the sequence was confirmed by DNA sequencing. The KpnI-HindIII fragment excised from pUChrcCdown was then inserted into pUChrcCup digested with KpnI and HindIII, resulting in pUChrcCupdown. A kanamycin-resistance gene, which was obtained by digestion of pEZ::TN with $P v u I I$ (Tsuge et al. 2002) was inserted at the KpnI site of pUChrcCupdown. The resulting plasmid was digested with EcoRI and HindIII, and the 4.5-kb fragment harboring the upstream region of the $h r c C$ gene, the kanamycin-resistance gene, and the downstream region of the $h r c C$ gene was inserted into modified pUC19 with the spectinomycin-resistance gene in place of the ampicillinresistance gene, resulting in pUCdeltahrcCKm. Next, marker exchange mutagenesis of strain ATCC33913 (Tsuge et al. 2001) was conducted using the plasmid pUCdeltahrcCKm. Marker exchange mutagenesis was confirmed by genomic Southern blot analysis (data not shown).

The 1.5-kb upstream and 1.2-kb downstream regions of the xopR (XOO_4134) gene that encodes one of the T3E were amplified from $X$. oryzae pv. oryzae MAFF311018 (Ochiai et al. 2005), using the following primer sets, respectively: $x o p R \_u p \_S$ (5'-ATGGATCCGGCAGCACGCAGCGACACGT AG- $\left.3^{\prime}\right)$ and XopR_up_AS (5'-TTGATATCCACTTACTCCTTT CGGACTGTC-3') for the upstream region and $x o p R \_$down_S (5'-AAGATATCTGAAAATCCTGACGGCCAGGAG-3') and $x o p R \_d o w n \_$AS $\left(5^{\prime}\right.$-GTGGAATTCAGTAACGGCTGCATCT
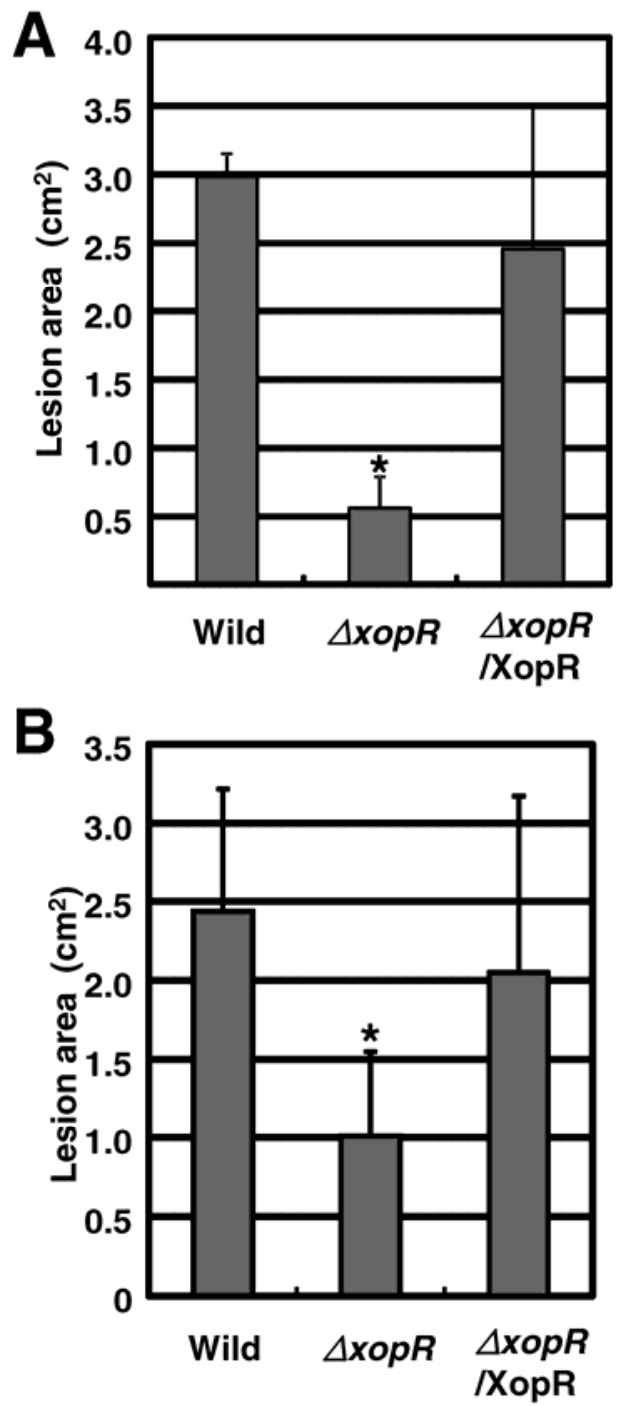

Fig. 6. Virulence assay on the $x o p R$ deletion mutant $(\triangle x o p R)$ and its complementing strains ( $\triangle x o p R / X o p R)$. Xanthomonas oryzae pv. oryzae bacteria were inoculated by leaf clipping, and the lesion area was measured 10 days after inoculation on two rice lines, A, IR24 and B, Nipponbare. At least six inoculated leaves were analyzed in each test. ${ }^{*} P<0.001$ vs. wild type by Student's $t$ test. 
GCTGC-3') for the downstream region. Each PCR fragment was cloned into the BamHI/EcoRV-digested pBR322 and EcoRI/EcoRV-digested pBluescript II SK+, respectively, to obtain pBRxopRup and pBSxopRdown, followed by sequence analysis. The EcoRI-EcoRV fragment excised from pBSxopRdown was then inserted into pBRxopRup digested with EcoRI and EcoRV to give pBRxopRupdown. A kanamycin-resistant gene that was obtained with $P v u I I-d i g e s t i o n$ of the pEZ::TN (Tsuge et al. 2002) was then inserted into pBRxopRupdown. Using the resulting plasmid pBRdeltaxopRKm, marker-exchange mutagenesis of strain MAFF311018 was conducted (Tsuge et al. 2001), resulting in a kanamycin-resistant and ampicillin-susceptible $x o p R$ deletion mutant $(\Delta x o p R)$. For the complementation test, an approximately $3.2-\mathrm{kb}$ SacI-HindIII fragment containing the xopR (XOO_4134) gene was inserted into the broad host-range vector pHM1 (Innes et al. 1988) to give $\mathrm{pHMxopR}$. The plasmid was introduced into a $\Delta x o p R$ bacteria, and the transformant was used as complemented strain.

\section{Virulence assays.}

$X$. campestris pv. campestris hrcC mutant bacteria were grown on NBY agar plates containing appropriate antibiotics for 1 day and were then resuspended in $10 \mathrm{mM} \mathrm{MgCl}_{2}$ at a concentration of $1 \times 10^{9} \mathrm{CFU} / \mathrm{ml}$. Five- to six-week-old Arabidopsis leaves were inoculated by piercing three holes in the central vein with a needle that had been dipped in the bacterial suspension. After inoculation, plants were kept under plastic covers for 1 day at $100 \%$ relative humidity and were then transferred to $65 \%$ relative humidity. For assays of bacterial growth in leaves, four leaves were weighed, ground in $1 \mathrm{ml}$ of $10 \mathrm{mM} \mathrm{MgCl}$, and were mixed with serial dilutions of bacteria on appropriate media to calculate bacterial numbers.

Wild type, $\Delta x o p R$, and $\Delta x o p R / X o p R$ of $X$. oryzae pv. oryzae were grown on a NBY agar plate and were suspended in water at an optical density of 0.5 at $600 \mathrm{~nm}$. Rice cvs. IR24 and Nipponbare (both susceptible to MAFF311018) were grown in a growth chamber set to a $28^{\circ} \mathrm{C} 14$-h light and $24^{\circ} \mathrm{C} 10$-h dark cycle. The fully expanded upper leaves of 5-week-old rice were inoculated by the clipping method (Kauffman et al. 1973), and the lesion area was measured using ImageJ software at 10 days postinoculation.

\section{Generation of transgenic Arabidopsis plant lines.}

The XopR reading frame directly fused to a C-terminal influenza HA tag was cloned into the pTA7001 vector (Aoyama and Chua 1997) in which xopR-HA is preceded by the DEXinducible Cauliflower mosaic virus $35 \mathrm{~S}$ promoter. Col-0 Arabidopsis was transformed with Agrobacterium sp. strain EHA105 carrying pTA7001::XopR-HA using the flower-dipping method (Clough and Bent 1998), modified as described by Logemann and associates (2006). Transgenic plants were selected using $10 \mu \mathrm{g}$ of hygromycin per milliliter. Homozygous transformants were selected in the T3 generation, and XopR expression was confirmed by semiquantitative RT-PCR after induction by spraying with a combination of $30 \mu \mathrm{M} \mathrm{DEX}$ and $0.01 \%$ Silwet L-77. Plants were grown at $22^{\circ} \mathrm{C}$ in environmentally controlled chambers with an 8-h-light and 16-h-dark cycle for inoculation tests and a 16-h-light and 8-h-dark cycle for collecting seeds.

\section{Semiquantitative and quantitative RT-PCR.}

Arabidopsis leaves transformed with XopR (five to six weeks old) were sprayed with $0.01 \%$ Silwet L-77 containing or not containing (mock) $30 \mu \mathrm{M}$ DEX. After $24 \mathrm{~h}$, the leaves were inoculated with $X$. campestris pv. campestris hrcC mutant. For analysis of gene expression, total RNA was extracted using a RNeasy mini kit (Qiagen, Germantown, MD, U.S.A.). First-strand cDNA was synthesized from $500 \mathrm{ng}$ of total RNA, using a PrimeScript RT reagent kit (Takara Bio Inc., Otsu, Japan) with an oligo(dT) primer and a random 6-mer primer, according to the manufacturer's instructions. For semiquantitative RT-PCR, $50 \mathrm{ng}$ of cDNA was used for PCR, and all products were separated by electrophoresis on $1 \%$ agarose gels and were visualized by ethidium bromide staining. For quantitative RT-PCR, 20 ng of cDNA was combined with SYBR premix Ex Taq (Takara Bio Inc.). PCR analyses were performed in triplicate with a MX 3000P (Agilent Technologies, Santa Clara, CA, U.S.A.), with actin RNA as an internal control. Primers for genes were as follows: FRK1 (At2g19190), 5'-ATC

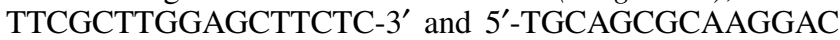
TAGAG-3'; At $1 g 51890,5^{\prime}$-CCAGTTTGTTCTGTAATACTCA GG-3' and 5'-CTAGCCGACTTTGGGCTATC-3'; At2g17740, 5'-TGCTCCATCTCTCTTTGTGC-3' and 5'-ATGCGTTGCT GAAGAAGAGG-3'; At5g57220, 5'-AATGGAGAGAGCAAC ACAATG-3' and 5'-ATACTGAGCATGAGCCCTTTG-3'; actin, 5'-AGTGGTCGTACAACCGGTATTGT-3' and 5'-GAGGAAG AGCATTCCCCTCGTA-3'; XopR, 5'-CAGGACTGATGCGG TGAACAAT- $3^{\prime}$ and 5'-CCAGGCACATCATAGGCAGTC-3'.

\section{Callose assays.}

The peptide flg22 was a gift from H. Kaku, Meiji University, Japan. Callose assays were performed as described previously (Goel et al. 2008), with minor modifications. Briefly, 5to 6-week-old plants were sprayed with $30 \mu \mathrm{M}$ DEX. After 24 $\mathrm{h}$, plants were infused with $1 \mathrm{mM}$ flg22. After another $8 \mathrm{~h}$, six leaves from independent plants were washed and stained with $0.01 \%$ aniline blue in $70 \mathrm{mM} \mathrm{K} \mathrm{HPO}_{4}, \mathrm{pH} 9.5$. Autofluorescent callose spots were analyzed by fluorescence microscopy (Nikon, Tokyo, Japan) excited by light in the UV spectrum. For each experiment, the number of callose loci was counted in six random microscopic fields.

\section{Generation of a Gateway vector for estradiol-induced expression of C-terminally Citrine-HA-tagged protein.}

The pMDC7-Citrine-HA vector was constructed by amplifying the full-length coding region of Citrine (Griesbeck et al. 2001), a variant of YFP, using primers 5'-TCCTTAATTAACA TGGTGAGCAAGGGCGAGGAGCTGTTC-3' (forward) and 5'-CTCGGCATGGACGAGCTGTACAAGTATCCATATGAC GTCCCAGACTATGCCTGAACTAGTGC-3' (reverse). The reverse primer included the sequence for the HA tag followed by a stop codon. This amplicon was ligated downstream of the Invitrogen Gateway site in the binary vector pMDC7 (Curtis and Grossniklaus 2003) after digestion with PacI and SpeI. The open reading frame of XopR $\left(\mathrm{XOO}_{-} 4134\right)$ was cloned into the pENTR/d-TOPO vector (Invitrogen), and XopR::Citrine:: HA was generated by LR (Invitrogen) according to the manufacturer's instructions.

\section{Transient expression}

of Xop::Citrine protein in Nicotiana benthamiana.

A. tumefaciens EHA105 transformed with either XopR:: Citrine in pMDC7 or HC-Pro of Potato virus $Y$ (a silencing suppressor protein) in pMD1 (Kubota et al. 2003) were cultivated overnight at $28^{\circ} \mathrm{C}$ in the presence of appropriate antibiotics. Bacterial cells were collected by centrifugation and were resuspended in induction buffer $(10 \mathrm{mM} \mathrm{MgCl} 2$ and $10 \mathrm{mM}$ MES, pH 5.6, supplemented with $0.5 \mathrm{mM}$ acetosyringone) and were incubated for $2 \mathrm{~h}$ with gentle mixing. Bacteria were diluted with induction buffer to a final optical density at 600 $\mathrm{nm}$ of 1.0 for XopR::Citrine and 0.1 for Hc-Pro and were then co-infused into the leaves of 4- to 6-week-old plants, using a needleless syringe. Two days after infiltration, leaves were sprayed with a combination of $30 \mu \mathrm{M}$ 17-estradiol (Sigma- 
Aldrich, St. Louis) and $0.01 \%$ Silwet L-77 to induce protein expression. After 1 day, the expression and accumulation of Xop::Citrine protein in plant cells were observed using a TCS SP5 confocal microscope (Leica Microsystems, Solms, Germany). For nucleic acid stain, $10 \mu \mathrm{g}$ of propidium iodide per milliliter (Sigma-Aldrich) was used.

\section{Protein extraction and immunoblot analysis.}

Four leaves of 6-week-old XopR transgenic Arabidopsis were collected, and total protein was isolated by homogenization in $300 \mu \mathrm{l}$ of sodium dodecyl sulfate (SDS) sample buffer (125 $\mathrm{mM}$ Tris- $\mathrm{HCl}, \mathrm{pH} 6.8,4 \%$ SDS, $20 \%$ glycerol, and 10\% 2-mercaptoethanol) and was then clarified by centrifugation at $10,000 \times g$. The extracts were subjected to SDS-polyacrylamide gel electrophoresis (PAGE) and immunoblot analysis with anti-HA antibody (Medical \& Biological Laboratories, Nagoya, Japan).

Proteins were fractionated as described previously (Holt et al. 2005) with minor modifications. Briefly, four disks of $N$. benthamiana leaf tissue $\left(0.8 \mathrm{~cm}^{2}\right)$ were homogenized in $500 \mu \mathrm{l}$ of extraction buffer (20 mM Tris- $\mathrm{HCl}, \mathrm{pH} 8.0,0.33 \mathrm{M}$ sucrose, $1 \mathrm{mM}$ EDTA, $\mathrm{pH}$ 8.0, $10 \mu \mathrm{M}$ dithiothreitol, and protease inhibitor cocktail for plant cell and tissue extracts [SigmaAldrich]). The homogenate was centrifuged at $2,000 \times g$ for 5 min to remove plant debris. A $400-\mu$ l sample of the protein solution was centrifuged at $15,000 \times g$ for $1 \mathrm{~h}$ at $4^{\circ} \mathrm{C}$. The pellet containing the membrane fraction was resuspended in 100 $\mu \mathrm{l}$ of extraction buffer and was supplemented with $100 \mu \mathrm{l}$ of $2 \times$ SDS-PAGE loading buffer. The supernatant (around $400 \mu \mathrm{l}$ ) and total protein $(100 \mu \mathrm{l})$ were mixed with $400 \mu \mathrm{l}$ and $100 \mu \mathrm{l}$ of $2 \times$ SDS-PAGE loading buffer, respectively. After boiling for $10 \mathrm{~min}$ at $95^{\circ} \mathrm{C}, 20 \mu \mathrm{l}$ of each sample was separated by gel electrophoresis on a $10 \%$ acrylamide gel and was then electrophoretically transferred onto a Hybond-P membrane (GE Healthcare, Buckinghamshire, U.K.). Citrine-tagged XopR was detected with mouse monoclonal anti-GFP antibodies (Medical \& Biological Laboratories), followed by peroxidaseconjugated anti-mouse antibodies (Sigma-Aldrich), and finally, ECL Plus Western blotting detection reagents (GE Healthcare). For fractionation control, rabbit anti-aquaporin antibodies (Cosmo Bio, Tokyo, Japan) and anti-APX (cytosolic ascorbate peroxidase) antibodies (Cosmo Bio) were used.

\section{ACKNOWLEDGMENTS}

We thank T. Meshi, National Institute of Agrobiological Sciences for kindly providing HC-Pro in pMD1 and S. Mochizuki for helpful advice on microscopic observation. We also thank C. Setoyama for assistance.

\section{LITERATURE CITED}

Abramovitch, R. B., Anderson, J. C., and Martin, G. M. 2006. Bacterial elicitation and evasion of plant innate immunity. Nat. Rev. Mol. Cell Biol. 7:601-611.

Alfano, J. R., and Collmer, A. 1997. The type III (Hrp) secretion pathway of plant pathogenic bacteria: Trafficking harpins, Avr proteins, and death. J. Bacteriol. 179:5655-5662.

Alfano, J. R., and Collmer, A. 2004. Type III secretion system effector proteins: Double agents in bacterial disease and plant defense. Annu. Rev. Phytopathol. 42:385-414.

Aoyama, T., and Chua, N. H. 1997. A glucocorticoid-mediated transcriptional induction system in transgenic plants. Plant J. 11:605-612.

Bartetzko, V., Sonnewald, S., Vogel, F., Hartner, K., Stadler, R., Hammes, U. Z., and Frederik, B. 2009. The Xanthomonas campestris pv. vesicatoria type III effector protein XopJ inhibits protein secretion: Evidence for interference with cell wall-associated defense responses. Mol. Plant-Microbe Interact. 22:655-664.

Boch, J., Scholze, H., Schornack, S., Landgraf, A., Hahn, S., Kay, S., Lahaye, T., Nickstadt, A., and Bonas, U. 2009. Breaking the code of DNA binding specificity of TAL-type III effectors. Science 326:1509-1512.
Boller, T., and He, S.Y. 2009. Innate immunity in plants: An arms race between pattern recognition receptors in plants and effectors in microbial pathogens. Science 324:742-744.

Brown, I. R., Mansfield, J. W., and Bonas, U. 1995. Hrp genes in Xanthomonas campestris pv. vesicatoria determine ability to suppress papilla deposition in pepper mesophyll cells. Mol. Plant-Microbe Interact. 8:825-836.

Büttner, D., and Bonas, U. 2006. Who comes first? How plant pathogenic bacteria orchestrate type III secretion. Curr. Opin. Microbiol. 9:193-200.

Büttner, D., and He, S. Y. 2009. Type III protein secretion in plant pathogenic bacteria. Plant Physiol. 150:1656-1664.

Clay, N. K., Adio, A. M., Denoux, C., Jander, G., and Ausubel, F. M. 2009. Glucosinolate metabolites required for an Arabidopsis innate immune response. Science 323:95-101.

Clough, S. J., and Bent, A. F. 1998. Floral dip: A simplified method for Agrobacterium-mediated transformation of Arabidopsis thaliana. Plant J. 16:735-743.

Curtis, M. D., and Grossniklaus, U. 2003. A gateway cloning vector set for high-throughput functional analysis of genes in planta. Plant Physiol. 133:462-469.

da Silva, A. C., Ferro, J. A., Reinach, F. C., Farah, C. S., Furlan, L. R., Quaggio, R. B., Monteiro-Vitorello, C. B., Van Sluys, M. A., Almeida, N. F., Alves, L. M., do Amaral, A. M., Bertolini, M. C., Camargo, L. E., Camarotte, G., Cannavan, F., Cardozo, J., Chambergo, F., Ciapina, L. P., Cicarelli, R. M., Coutinho, L. L., Cursino-Santos, J. R., El Dorry, H., Faria, J. B., Ferreira, A. J., Ferreira, R. C., Ferro, M. I., Formighieri, E. F., Franco, M. C., Greggio, C. C., Gruber, A., Katsuyama, A. M., Kishi, L. T., Leite, R. P., Lemos, E. G., Lemos, M. V., Locali, E. C., Machado, M. A., Madeira, A. M., Martinez-Rossi, N. M., Martins, E. C., Meidanis, J., Menck, C. F., Miyaki, C. Y., Moon, D. H., Moreira, L. M., Novo, M. T., Okura, V. K., Oliveira, M. C., Oliveira, V. R., Pereira, H. A., Rossi, A., Sena, J. A., Silva, C., de Souza, R. F., Spinola, L. A., Takita, M. A., Tamura, R. E., Teixeira, E. C., Tezza, R. I., Trindade dos, S. M., Truffi, D., Tsai, S. M., White, F. F., Setubal, J. C., and Kitajima, J. P. 2002. Comparison of the genomes of two Xanthomonas pathogens with differing host specificities. Nature 417:459-463.

Dowen, R. H., Engel, J. L., Shao, F., Ecker, J. R., and Dixon, J. E. 2009. A family of bacterial cysteine protease type III effectors utilizes acylationdependent and -independent strategies to localize to plasma membranes. J. Biol. Chem. 284:15867-15879.

Furutani, A., Takaoka, M., Sanada, H., Noguchi, Y., Oku, T., Tsuno, K., Ochiai, H., and Tsuge, S. 2009. Identification of novel type III secretion effectors in Xanthomonas oryzae pv. oryzae. Mol Plant-Microbe Interact. 22:96-106.

Goel, A. K., Lundberg, D., Torres, M. A., Matthews, R., AkimotoTomiyama, C., Farmer, L., Dangl, J. L., and Grant, S. R. 2008. The Pseudomonas syringae type III effector HopAM1 enhances virulence on water-stressed plants. Mol. Plant-Microbe. Interact. 21:361-370.

Göhre, V., Spallek, T., Häweker, H., Mersmann, S., Mentzel, T., Boller, T., de Torres, M., Mansfield, J. W., and Robatzek, S. 2008. Plant patternrecognition receptor FLS2 is directed for degradation by the bacterial ubiquitin ligase AvrPtoB. Curr. Biol. 18:1824-1832.

Gomez-Gomez, L., and Boller, T. 2002. Flagellin perception: A paradigm for innate immunity. Trends Plant Sci. 7:251-256.

Grant, S. R., Fisher, E. J., Chang, J. H., Mole, B. M., and Dangl, J. L. 2006. Subterfuge and manipulation: Type III effector proteins of phytopathogenic bacteria. Annu. Rev. Microbiol. 60:425-449.

Griesbeck, O., Baird, G. S, Campbell, R. E., Zacharias, D. A., and Tsien, R.Y. 2001. Reducing the environmental sensitivity of yellow fluorescent protein. Mechanism and applications. J. Biol. Chem. 276:29188-29194.

Gu, K., Yang, B., Tian, D., Wu, L., Wang, D., Sreekala, C., Yang, F., Chu, Z., Wang, G. L., White, F. F., and Yin, Z. 2005. R gene expression induced by a type-III effector triggers disease resistance in rice. Nature 435:1122-1125.

He, P., Shan, L., Lin, N. C., Martin, G. B., Kemmerling, B., Nurnberger, T., and Sheen, J. 2006. Specific bacterial suppressors of MAMP signaling upstream of MAPKKK in Arabidopsis innate immunity. Cell 125:563-575.

He, P., Shan, L., and Sheen, J. 2007. Elicitation and suppression of microbeassociated molecular pattern-triggered immunity in plant-microbe interactions. Cell Microbiol. 9:1385-1396.

Holt, B. F., III, Belkhadir, Y., and Dangl, J. L. 2005. Antagonistic control of disease resistance protein stability in the plant immune system. Science 309:929-932.

Innes, R. W., Hirose, M. A., and Kuempel, P. L. 1988. Induction of nitrogen-fixing nodules on clover requires only 32 kilobase pairs of DNA from Rhizobium trifolii symbiosis plasmid. J. Bacteriol. 170:3793-3802.

Jelenska, J., Yao, N., Vinatzer, B. A., Wright, C. M., Brodsky, J. L., and Greenberg, J. T. 2007. A J domain virulence effector of Pseudomonas syringae remodels host chloroplasts and suppresses defenses. Curr. 
Biol. 17:499-508.

Kaku, H., Nishizawa, Y., Ishii-Minami, N., Akimoto-Tomiyama, C., Dohmae, N., Takio, K., Minami, E., and Shibuya, N. 2006. Plant cells recognize chitin fragments for defense signaling through a plasma membrane receptor. Proc. Natl. Acad. Sci. U.S.A. 103:11086-11091.

Kauffman, H. E., Reddy, A. P. K., Hsieh, S. P. Y., and Merca, S. D. 1973. An improved technique for evaluating resistance to rice varieties of Xanthomonas oryzae. Plant Dis. Rep. 57:537-541.

Kay, S., and Bonas, U. 2009. How Xanthomonas type III effectors manipulate the host plant. Curr. Opin. Microbiol. 12:37-43.

Kim J. G., Taylor, K. W., Hotson, A., Keegan, M. Schmelz, E. A., and Mudgett, M. B. 2008. XopD SUMO protease affects host transcription, promotes pathogen growth, and delays symptom development in Xanthomonas-infected tomato leaves. Plant Cell. 20:1915-1929.

Kim, J. G., Li, X., Roden, J. A., Taylor, K. W., Aakre, C. D., Su, B., Lalonde, S., Kirik, A., Chen, Y., Baranage, G., McLane, H., Martin, G. B., and Mudgett, M. B. 2009. Xanthomonas T3S effector XopN suppresses PAMP-triggered immunity and interacts with a Tomato atypical receptor-like kinase and TFT1. Plant Cell 21:1305-1323.

Knodler, L. A., Ibarra, J. A., Pérez-Rueda, E., Yip, C. K., and SteeleMortimer, O. 2011. Coiled-coil domains enhance the membrane association of Salmonella type III effectors. Cell Microbiol. 13:1497-1517.

Kubota, K., Tsuda, S., Tamai, A., and Meshi, T. 2003. Tomato mosaic virus replication protein suppresses virus-targeted posttranscriptional gene silencing. J. Virol. 77:11016-11026.

Lee, B. M., Park, Y. J., Park, D. S., Kang, H. W., Kim, J. G., Song, E. S., Park, I. C., Yoon, U. H., Hahn, J. H., Koo, B. S., Lee, G. B., Kim, H., Park, H. S., Yoon, K. O., Kim, J. H., Jung, C., Koh, N. H., Seo, J. S., and Go, S. J. 2005. The genome sequence of Xanthomonas oryzae pathovar oryzae KACC10331, the bacterial blight pathogen of rice. Nucleic Acids Res. 33:577-586.

Lindeberg, M., Stavrinides, J., Chang, J. H., Alfano, J. R., Collmer, A., Dangl, J. L, Greenberg, J T.. Mansfield, J. W. and Guttman, D. S. 2005. Proposed guidelines for a unified nomenclature and phylogenetic analysis of type III Hop effector proteins in the plant pathogen Pseudomonas syringae. Mol. Plant-Microbe. Interact. 18:275-282.

Logemann, E., Birkenbihl, R. P., Uler, B., and Somssich, I. E. 2006. An improved method for preparing Agrobacterium cells that simplifies the Arabidopsis transformation protocol. Plant Methods 2:16.

Meyer, D., Lauber, E., Roby, D., Arlat, M., and Kroj, T. 2005. Optimization of pathogenicity assays to study the Arabidopsis thaliana-Xanthomonas campestris pv. campestris pathosystem. Mol. Plant Pathol. 6:327-333.

Miller, J. C., Tan, S., Qiao, G., Barlow, K. A., Wang, J., Xia, D. F., Meng, X., Paschon, D. E., Leung, E., and Hinkley, S. J. 2011. A TALE nuclease architecture for highly efficient genome editing. Nat. Biotechnol. 29:143148

Miller, J. H. 1972. Experiments in Molecular Genetics. Cold Spring Harbor Laboratory Press, Cold Spring Harbor, NY, U.S.A.

Miya, A., Albert, P., Shinya, T., Desaki, Y., Ichimura, K., Shirasu, K., Narusaka, Y., Kawakami, N., Kaku, H., and Shibuya, N. 2007. CERK1, a LysM receptor kinase, is essential for chitin elicitor signaling in Arabidopsis. Proc. Natl. Acad. Sci. U.S.A. 104:19613-19618.

Nimchuk, Z., Marois, E., Kjemtrup, S., Leister, R. T., Katagiri, F., and Dangl, J. L. 2000. Eukaryotic fatty acylation drives plasma membrane targeting and enhances function of several type III effector proteins from Pseudomonas syringae. Cell 101:353-363.

Ochiai, H., Inoue, Y., Takeya, M., Sasaki, A., and Kaku, H. 2005. Genome sequence of Xanthomonas oryzae pv. oryzae suggests contribution of large numbers of effector genes and insertion sequences to its race diversity. Jpn. Agric. Res. Q. 39:275-287.

Robert-Seilaniantz, A., Shan, L., Zhou, J.-M., and Tang, X. 2006. The Pseudomonas syringae pv. tomato DC3000 type III effector HopF2 has a putative myristoylation site required for its avirulence and virulence functions. Mol. Plant-Microbe. Interact. 19:130-138.

Salzberg, S. L, Sommer, D. D., Schatz, M. C., Phillippy, A. M., Rabinowicz,
P. D., Tsuge, S., Furutani, A., Ochiai, H., Delcher, A. L., Kelley, D. Madupu, R., Puiu, D., Radune, D., Shumway, M., Trapnell, C., Aparna, G., Jha, G., Pandey, A., Patil, P. B., Ishihara, H., Meyer, D. F., Szurek, B., Verdier, V., Koebnik, R., Dow, J. M., Ryan, R. P., Hirata, H., Tsuyumu, S., Won Lee, S., Seo, Y. S., Sriariyanum, M., Ronald, P. C., Sonti, R. V., Van Sluys, M. A., Leach, J. E., White, F. F., and Bogdanove, A. J. 2008. Genome sequence and rapid evolution of the rice pathogen Xanthomonas oryzae pv. oryzae PXO99A. BMC Genomics 9:204.

Scholze, H., and Boch, J. 2011. TAL effectors are remote controls for gene activation. Curr. Opin. Microbiol. 14:47-53.

Shan, L., Thara, V. K., Martin, G. B., Zhou, J. M., and Tang, X. 2000. The Pseudomonas AvrPto protein is differentially recognized by tomato and tobacco and is localized to the plant plasma membrane. Plant Cell $12: 2323-2338$

Shimizu, T., Nakano, T., Takamizawa, D., Desaki, Y., Ishii-Minami, N., Nishizawa, Y., Minami, E., Okada, K., Yamane, H., Kaku, H., and Shibuya, N. 2010. Two LysM receptor molecules, CEBiP and OsCERK1, cooperatively regulate chitin elicitor signaling in rice. Plant J. 64:204-214.

Song, C., and Yang, B. 2010. Mutagenesis of 18 type III effectors reveals virulence function of $\mathrm{XopZ}_{\mathrm{PXO} 99}$ in Xanthomonas oryzae pv. oryzae. Mol. Plant-Microbe. Interact. 23:893-902.

Takai, R., Isogai, A., Takayama, S., and Che, F. S. 2008. Analysis of flagellin perception mediated by flg22 receptor OsFLS2 in rice. Mol. Plant-Microbe. Interact. 21:1635-1642.

Thieme, F., Szczesny, R., Urban, A., Kirchner, O., Hause, G., and Bonas, U. 2007. New type III effectors from Xanthomonas campestris pv. vesicatoria trigger plant reactions dependent on a conserved $\mathrm{N}$-myristoylation motif. Mol. Plant-Microbe. Interact. 20:1250-1261.

Tsuge, S., Furutani, A., Fukunaka, R., Kubo, Y., and Horino, O. 2001. Growth complementation of hrpXo mutants of Xanthomonas oryzae pv. oryzae by virulent strains in rice cultivars resistant and susceptible to the parental strain. J. Gen. Plant Pathol. 67:51-57.

Tsuge, S., Furutani, A., Fukunaka, R., Oku, T., Tsuno, K., Ochiai, H., Inoue, Y., Kaku H., and Kubo Y. 2002. Expression of Xanthomonas oryzae pv. oryzae hrp genes in a novel synthetic medium, XOM2. J. Gen. Plant Pathol. 68:363-371.

Vidaver, A. K. 1967. Synthetic and complex media for the rapid detection of fluorescence of phytopathogenic pseudomonads: Effect of the carbon source. Appl. Microbiol. 15:1523-1524.

Vieira, J., and Messing, J. 1987. Production of single-stranded plasmid DNA. Methods Enzymol. 153:3-11.

White, F. F., Potnis, N., Jones, J. B., and Koebnik, R. 2009. The type III effectors of Xanthomonas. Mol. Plant Pathol. 10:749-766.

Xiang, T., Zong, N., Zou, Y., Wu, Y., Zhang, J., Xing, W., Li, Y., Tang, X., Zhu, L., Chai, J., and Zhou, J. M. 2008. Pseudomonas syringae effector AvrPto blocks innate immunity by targeting receptor kinases. Curr. Biol. 18:74-80.

Yang, B., Sugio, A., and White, F. F. 2005. Avoidance of host recognition by alterations in the repetitive and C-terminal regions of AvrXa7, a type III effector of Xanthomonas oryzae pv. oryzae. Mol. Plant-Microbe Interact. 18:142-149.

Zhang, J., Shao, F., Li, Y., Cui, H., Chen, L., Li, H., Zou, Y., Long, C., Lan, L., Chai, J., Chen, S., Tang, X., and Zhou, J. M. 2007. A Pseudomonas syringae effector inactivates MAPKs to suppress PAMP-induced immunity in plants. Cell Host Microbe 17:175-185.

Zipfel, C., Robatzek, S., Navarro, L., Oakeley, E. J., and Jones, J. D. 2004 Bacterial disease resistance in Arabidopsis through flagellin perception. Nature 428:764-767.

\section{AUTHOR-RECOMMENDED INTERNET RESOURCES}

The COILS prediction program:

www.ch.embnet.org/software/COILS_form.html

ImageJ software: rsbweb.nih.gov/ij 